\title{
Outcomes and Relevant Factors Associated with Cardiac Dysfunction in Patients with Traumatic Brain Injury
}

\author{
Yingrui Zhang, Hongxuan Zhang, Jun Li, Jianxiang Zhao, Han Chen, Jingqing Xu, Xiuling Shang, \\ Rongguo Yu* $^{*}$
}

Department of Surgical Critical Care, Fujian Provincial Hospital, Fujian Province Intensive Medical Center, Fujian Medical University Affiliated Provincial Teaching Hospital, Fuzhou, China

Email: sharona1001@126.com, zhx490260515@qq.com, lijun2006.hust@foxmail.com,113657050@qq.com, baojr2@163.com, xjq418@163.com, zksxling@163.com, *garyyrg@yahoo.com

How to cite this paper: Zhang, Y.R., Zhang, H.X., Li, J., Zhao, J.X., Chen, H., Xu, J.Q., Shang, X.L. and Yu, R.G. (2021) Outcomes and Relevant Factors Associated with Cardiac Dysfunction in Patients with Traumatic Brain Injury. Open Access Library Journal, 8: e7071.

https://doi.org/10.4236/oalib.1107071

Received: December 9, 2020

Accepted: January 17, 2021

Published: January 20, 2021

Copyright $\odot 2021$ by author(s) and Open Access Library Inc.

This work is licensed under the Creative Commons Attribution International License (CC BY 4.0).

http://creativecommons.org/licenses/by/4.0/

(c) (i) Open Access

\begin{abstract}
Purpose: Cardiac dysfunction has been rarely reported in patients with traumatic brain injury (TBI). The study aimed to compare clinical outcomes in patients admitted in intensive care unit (ICU) with normal cardiac function versus cardiac dysfunction after TBI. Moreover, the association of risk factors and hospital mortality ICU or hospital length of stay was investigated. Methods: A retrospective study was conducted from December 2011 to April 2018 on TBI patients admitted without pre-existing cardiac diseases. Patients with TBI were grouped into secondary cardiac dysfunction $(n=112)$ and normal cardiac function $(n=160)$ groups according to the presence of abnormal echocardiography after ICU admission. Univariate and multivariate analyses were performed. Results: Elevated BNP and troponin levels were found in the group with cardiac dysfunction. Patients with cardiac dysfunction had significantly higher hospital mortality (16.96\% vs. $8.13 \%)$, longer ICU length of stay (16.34 vs. $10.99 \mathrm{~d}$ ) than those without cardiac events. Cardiac dysfunction was an independent predictor of hospital mortality $(p<$ $0.001)$ and the ICU length of stay $(p<0.001)$ after adjusting confounders. Risk factors mainly associated with hospital length of stay were age $(p=$ $0.043)$, GCS score $(p<0.001)$, and use of mechanical ventilation $(p=0.013)$. GCS score $(p<0.001)$ use of vasopressor was related factors associated with ICU length of stay $(p=0.018)$. Conclusions: Cardiac dysfunction in context of TBI has a negative impact on clinical outcomes, and it is an independent predictor for increasing hospital mortality and longer ICU length of stay.
\end{abstract}

\section{Subject Areas}

Emergency, Critical Care 


\section{Keywords}

Intensive Care, Traumatic Brain Injury, Cardiac Function, Mortality

\section{Introduction}

Traumatic brain injury (TBI) is one of the most common diseases of the intensive care unit (ICU) worldwide, and over 3 - 4 million populations are affected annually in China [1] [2]. Patients with TBI are prone to develop secondary end-organ damage due to homeostasis changes, resulting in poor prognosis, increased mortality, and prolonged stay in the ICU [3] [4]. Under specific neurological conditions, brain injury may lead to brain-heart interactions and paroxysmal sympathetic hyperactivity (PSH) over the following days, even an impact on cardiac function and patients' outcomes negatively [5] [6]. Currently, such cardiac events after TBI are often thought to cause by elevated intracranial pressure (ICP) and excessive adrenergic activity, which results in increased sympathetic activity and electrocardiographic abnormalities [7] [8] [9]. Nevertheless, there are limited described neuro-cardiogenic dysfunctions in the context of TBI.

The presence of secondary cardiac dysfunction in patients with various neurological injuries is found to be associated with unfavorable clinical outcomes [10] [11] [12] [13]. One recent study demonstrated cardiac dysfunction in $22 \%$ of isolated TBI patients, including a reduced left ventricular ejection fraction (LVEF) and regional wall motion abnormalities, even correlated with increased in-hospital mortality [6]. Conversely, Najafi Pour et al. [14] conducted an animal study, presented that no cardiac events observed in an experimental rat model of diffuse TBI. Meanwhile, there is also evidence in a multitude of neurological conditions that the prognostic outcomes of cardiac function vary depending on multiple underlying factors, such as the severity of brain injury, relevant infections, and co-morbidity [11] [15] [16]. Therefore, the association of cardiac abnormalities after various brain injuries and patient's outcome remains controversial at present.

We retrospectively compared the clinical outcomes in patients with normal cardiac function versus cardiac dysfunction after TBI and its association with cardiac function, and further investigated risk factors associated with hospital mortality, ICU, and hospital length of stay.

\section{Methods}

We conducted a retrospective study of TBI patients admitted to surgical intensive care unit (SICU) at Fujian Provincial Hospital (Fujian, China) from December 2011 to April 2018. This SICU is dedicated to trauma/surgical, burn, organ transplantation, severe infection, and neurology/neurosurgery patients, and more than 600 critically ill patients admitted to this department per year. The study was approved by the institutional ethics committee of this hospital. 


\subsection{Patient Data}

Subjects for this study were extracted automatically from a big-data intelligence database platform (YiduCloud Technology Ltd., Beijing, China) by setting the criteria of cardiac dysfunction group and normal group. The cardiac dysfunction group in TBI patients (aged 18 - 80 years old) who have were classified by presence of abnormal findings with plasma brain natriuretic peptide (BNP), Cardiac troponin (cTn), vechocardiography and electrocardiogram during the ICU stay. TBI is defined as an alteration in brain function, or other evidence include visual, neuroradiology, or laboratory confirmation of damage to the brain of brain pathology, caused by an external force. They were generally categorized as mild (GCS 13 - 15), moderate (GCS 9 - 12), and severe (GCS 3 - 8) TBI [4]. The following patients were excluded: 1) patients with pre-existing primary cardiac diseases (arrhythmia, coronary heart disease, congenital heart disease, cardiac insufficiency or heart failure condition resulted from above diseases); 2) a medical history of post-cardiac surgery or cardiac intervention surgery; 3) patients with pre-existing diabetes, hypertension, chronic kidney disease, chronic obstructive pulmonary disease, hyperthyroidism, autoimmune diseases and other diseases which already cause cardiac dysfunction; 4) patients with a prior history of intracranial diseases; 5) patients who with multiple trauma or traumatic hemorrhagic shock; 6) patients who had stayed in the ICU $<48$ hours.

\subsection{Data Collection and Outcome Measures}

Demographic data including age, gender, and relevant risk factors (GCS score, health behaviors, CT diagnosis, and secondary infection) were collected from electronic medical records during the period of hospital admission. The following laboratory parameters were obtained during ICU admission, heart rate, respiratory rate, temperature, blood pressure (systolic and diastolic), lactate, hemoglobin (Hb), white blood cell count (WBC), blood urea nitrogen (BUN), creatinine (Cr) C-reactive protein (CRP), procalcitonin (PCT), life support modes (mechanical ventilation, inotropes or vasopressor) Moreover, cardiac enzyme data (creatine phosphokinase MB isoenzyme (CK-MB), troponin-I, B-type natriuretic peptide (BNP) were also recorded. The main clinical outcomes including ICU or hospital length of stay, hospital mortality were compared between the two groups. Risk factors contributing to hospital length of stay were also analyzed.

\subsection{Statistical Analysis}

All statistical analysis was conducted using SAS, version 9.4 (SAS Institute, Cary, $\mathrm{NC}$ ). All data were expressed as mean $\pm \mathrm{SD}$ (standard deviation) or median and interquartile range (IQR) as appropriate for continuous variables, while as percentages for categorical variables. We compared continuous variables using the Wilcoxon signed-rank test and categorical variables using chi-squared test. Variables (age, GCS score, blood urea nitrogen (BUN), creatinine (Cr), troponin-I 
and BNP) with a significant difference between the two groups in univariate analysis were included into the model. A multivariable logistic (linear) regression model was developed for investigating whether secondary cardiac abnormalities were associated with length of in-hospital stay and in-hospital cure rate after adjusting all confounders. Diagnostic performance of age, GCS, troponin-I, and BNP in predicting cardiac dysfunction were evaluated using receiver operating characteristic (ROC) curves. Moreover, we calculated the odds ratios (ORs) and $95 \%$ confidence intervals (95\% CIs) for mortality and ICU and hospital length of stay according to various factors using multiple logistic regression analysis. $P$ values $<0.05$ were considered statistically significant.

\section{Results}

\subsection{Patients Characteristics}

A total of 1404 patients with TBI between December 2011 to April 2018 were initially screened for this study. Of the enrolled 272 eligible participants, 112 TBI patients were included cardiac group, the other 160 patients were included normal group (Figure 1). Baseline characteristics of eligible patients are presented in Table 1. Patients with cardiac dysfunction after TBI were older than

Table 1. Baseline characteristics of eligible patients between the two groups.

\begin{tabular}{|c|c|c|c|}
\hline Characteristics & $\begin{array}{l}\text { Cardiac group } \\
\qquad(\mathrm{n}=112)\end{array}$ & $\begin{array}{l}\text { Normal group } \\
\qquad(\mathrm{n}=160)\end{array}$ & $p$ \\
\hline Age, years (Median, range) & $58(48.5-68.0)$ & $46(33.5-57.0)$ & $<0.001^{\star}$ \\
\hline Female, n (\%) & $28(25.00)$ & $42(26.25)$ & 0.817 \\
\hline Marital status $\mathrm{N}=95 / 141, \mathrm{n}(\%)$ & $89(79.46)$ & $123(76.88)$ & 0.203 \\
\hline \multicolumn{4}{|l|}{ Health behaviors, n (\%) } \\
\hline Smoking, $\mathrm{N}=103 / 153$ & $16(14.29)$ & $24(15.00)$ & 0.450 \\
\hline Alcohol use, $\mathrm{N}=104 / 148$ & $11(9.82)$ & $15(9.38)$ & 0.988 \\
\hline GCS, $N=106 / 150, n(\%)$ & & & 0.227 \\
\hline Severe $3-8$ & $63(56.25)$ & $78(48.75)$ & \\
\hline Moderate $9-12$ & $20(17.86)$ & $22(13.75)$ & \\
\hline Mild $13-15$ & $23(20.54)$ & $50(31.25)$ & \\
\hline \multicolumn{4}{|l|}{ CT diagnosis, n (\%) } \\
\hline Subarachnoid hemorrhage & $65(58.04)$ & $75(46.88)$ & 0.070 \\
\hline Intracranial hematomas & $88(78.57)$ & $108(67.50)$ & $0.045^{\star}$ \\
\hline Contusion & $40(35.71)$ & $78(48.75)$ & $0.033^{\star}$ \\
\hline \multicolumn{4}{|l|}{ Infection sources, $\mathrm{n}(\%)$} \\
\hline Pulmonary & $78(69.64)$ & $106(66.25)$ & 0.556 \\
\hline Intracranial & $7(6.25)$ & $11(6.88)$ & 0.838 \\
\hline Urethra & $12(10.71)$ & $14(8.75)$ & 0.588 \\
\hline Abdomen & $1(0.89)$ & 0 & 0.231 \\
\hline
\end{tabular}

${ }^{\star} p<0.05$ is considered statistically significant. Baseline characteristics of eligible patients are presented. Patients with cardiac dysfunction after TBI were older than those in the normal group (58 vs. $46, p<0.001)$. More patients with cerebral hemorrhage $(p=0.045)$ and contusion $(p=0.033)$ were found in the normal group. 


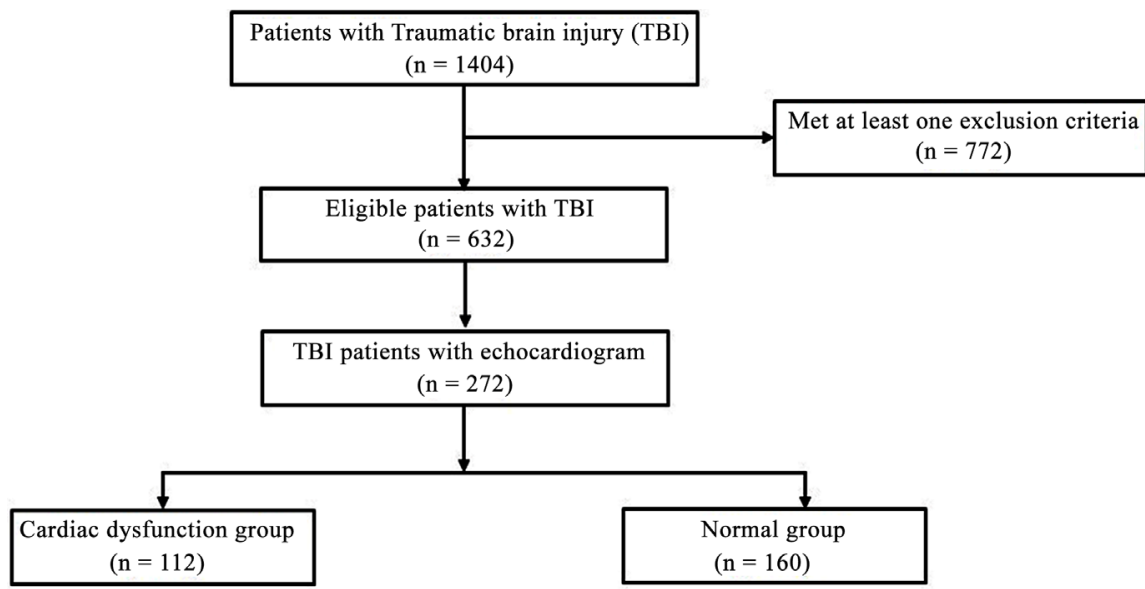

Figure 1. Patients characteristics of the flow chart of the study population.

those in the normal group (58 vs. $46, p<0.001$ ). More patients with cerebral hemorrhage $(p=0.045)$ and contusion $(p=0.033)$ were found in the normal group.

\subsection{Comparison of Clinical Characteristics}

Table 2 shows the comparison of clinical characteristics between the two groups. There was no difference between the two groups regarding clinical inflammatory markers (CRP, PCT, lactate), and routine blood indicators (Hb and WBC). BUN and $\mathrm{Cr}$ level were significantly elevated in the cardiac group $(p<0.001)$. For cardiac enzymes, the median levels of troponin $(p=0.004)$ and BNP $(p<0.001)$ in TBI patients with cardiac dysfunction were significantly higher than those without cardiac abnormalities.

\subsection{Comparisons of Clinical Outcomes}

The median ICU length of stay in TBI patients with cardiac dysfunction was longer than those with normal cardiac function (16.34 vs.10.99 d) $(p=0.048)$. The hospital mortality in the cardiac group was $16.96 \%$, while there was lower percentage of deaths $(8.13 \%)$ in the control group $(p<0.001)$ (Table 3$)$.

The effect of cardiac dysfunction on each outcome was also assessed by univariate and multivariate logistic (linear) regression through controlling variables, including age, number of cerebral hemorrhage and contusion, BUN, troponin and BNP levels (Table 4). Cardiac dysfunction in the setting of TBI was an independent factor affected hospital mortality and ICU length of stay (odds ratio $[\mathrm{OR}]=6.660,95 \%$ confidence interval $[\mathrm{CI}] 2.39-18.61, p<0.001$; and $\operatorname{Exp}(\mathrm{B}) \quad=$ $0.132,95 \%$ CI $0.08-0.19, p<0.001$, respectively).

The diagnostic performances of age, GCS, levels of troponin, and BNP in predicting cardiac events are summarized in Table 5. Age was good at predicting cardiac dysfunction with an area under the receiver operating characteristic curve (AUC) of 0.70. The AUC of elevated cardiac enzymes (troponin and BNP) in predicting cardiac dysfunction was 0.61 and 0.66 , respectively (Figure 2).

The factors in Table 6 associated with hospital mortality, hospital, and ICU 
Table 2. Comparisons of clinical characteristics between the two groups.

\begin{tabular}{|c|c|c|c|}
\hline Characteristics & $\begin{array}{l}\text { Cardiac group } \\
\quad(\mathrm{n}=112)\end{array}$ & $\begin{array}{l}\text { Normal group } \\
\quad(\mathrm{n}=160)\end{array}$ & $p$ \\
\hline Heart rate (per minute), & $84.5(70.0-103.5)$ & $88.0(77.0-101.0)$ & 0.737 \\
\hline $\begin{array}{l}\text { Respiratory rate (cycles/per min), } \\
\qquad N=105 / 147\end{array}$ & $20.0(18.0-20.0)$ & $20.0(18.0-21.0)$ & 0.396 \\
\hline Temperature $\left({ }^{\circ} \mathrm{C}\right), \mathrm{N}=106 / 147$ & $36.7(36.4-37.2)$ & $36.7(36.5-37.2)$ & 0.468 \\
\hline \multicolumn{4}{|l|}{ Blood Pressure, $N=104 / 142$} \\
\hline Diastolic pressure & $74.0(65.0-84.5)$ & $76.0(67.0-86.0)$ & 0.519 \\
\hline Systolic pressure & $132.0(120.0-151.5)$ & $131.5(119.0-146.0)$ & 0.231 \\
\hline $\mathrm{PaCO}_{2}(\mathrm{mmHg}), \mathrm{N}=98 / 133$ & $38.66 \pm 7.84$ & $39.20 \pm 6.91$ & 0.580 \\
\hline Lactate, $\mathrm{N}=97 / 133$ & $2.0(1.2-3.0)$ & $1.7(1.1-2.7)$ & 0.094 \\
\hline $\operatorname{HGB}(\mathrm{g} / \mathrm{L}), \mathrm{N}=110 / 160$ & $130.2(115.0-147.0)$ & $133.0(115.0-144.0)$ & 0.798 \\
\hline $\mathrm{WBC}(\mathrm{g} / \mathrm{L}), \mathrm{N}=110 / 160$ & $13.1(9.2-17.1)$ & $13.4(9.0-17.4)$ & 0.842 \\
\hline $\mathrm{BUN}(\mathrm{mmol} / \mathrm{L}), \mathrm{N}=110 / 159$ & $5.3(4.4-6.4)$ & $4.4(3.6-5.9)$ & $<0.001^{*}$ \\
\hline $\mathrm{Cr}$ (ummol/L), $\mathrm{N}=110 / 159$ & $72.5(56.0-89.0)$ & $68.0(55.0-79.0)$ & $0.045^{\star}$ \\
\hline $\mathrm{CRP}(\mathrm{mg} / \mathrm{L}), \mathrm{N}=91 / 128$ & $43.5(12.1-122.0)$ & $43.8(11.8-98.4)$ & 0.454 \\
\hline PCT $(\mu \mathrm{g} / \mathrm{mL}), \mathrm{N}=96 / 134$ & $0.28(0.06-1.39)$ & $0.31(0.09-1.12)$ & 0.851 \\
\hline Mechanical ventilation ( $\mathrm{n}, \%)$ & $104(92.86)$ & $142(88.75)$ & 0.257 \\
\hline Vasopressor use, $N=111 / 159,(n, \%)$ & $97(86.61)$ & $122(76.25)$ & 0.086 \\
\hline $\mathrm{CK}-\mathrm{MB}(\mathrm{U} / \mathrm{L}), \mathrm{N}=109 / 158$ & $14.3(10.0-26.5)$ & $15.5(11.0-29.1)$ & 0.217 \\
\hline Troponin $\mathrm{I}(\mathrm{ng} / \mathrm{ml}), \mathrm{N}=91 / 118$ & $0.02(0.01-0.16)$ & $0.01(0.00-0.04)$ & $0.004^{*}$ \\
\hline $\mathrm{BNP}(\mathrm{pg} / \mathrm{ml}), \mathrm{N}=95 / 117$ & $255.8(108.3-763.1)$ & $142.0(54.2-311.7)$ & $<0.001^{*}$ \\
\hline
\end{tabular}

HGB: hemoglobin; WBC: White blood cell; BUN: blood urea nitrogen; Cr: Creatinine; CRP: C-reactive protein; PCT: procalcitonin; BNP: type B natriuretic peptide-B. ${ }^{*} p<0.05$ is considered statistically significant.

Table 3. Comparison of clinical outcomes between the cardiac dysfunction and normal groups.

\begin{tabular}{cccc}
\hline Characteristics & $\begin{array}{c}\text { Cardiac group } \\
(\mathrm{n}=112)\end{array}$ & $\begin{array}{c}\text { Normal group } \\
(\mathrm{n}=160)\end{array}$ & $p$ \\
\hline hospital length of stay (days) (Median, range) & $53.0(30.0-90.0)$ & $47.0(25.5-87.0)$ & 0.690 \\
ICU length of stay (days) & $16.34(6.84-31.17)$ & $10.99(4.86-28.96)$ & $0.048^{*}$ \\
hospital Mortality, n (\%) & $16(16.96)$ & $13(8.13)$ & $<0.001^{*}$ \\
\hline
\end{tabular}

${ }^{*} p<0.05$ is considered statistically significant. The median ICU length of stay in TBI patients with cardiac dysfunction was longer than those with normal cardiac function ( $16.34 \mathrm{vs.10.99} \mathrm{d)}(p=0.048)$. The hospital mortality in the cardiac group was $16.96 \%$, while there was lower percentage of deaths $(8.13 \%)$ in the control group $(p<0.001)$.

Table 4. Multivariate logistic (linear) regression analysis of abnormal echocardiography associated with hospital mortality and length of stay.

\begin{tabular}{cccc}
\hline Characteristics & Adjusted OR or Exp (B) & $95 \%$ confidence interval & $p$ \\
\hline Hospital mortality & 6.660 & $2.39-18.61$ & $<0.001^{*}$ \\
Hospital length of stay & 0.015 & $-0.02-0.04$ & 0.343 \\
ICU length of stay & 0.132 & $0.08-0.19$ & $<0.001^{*}$ \\
\hline
\end{tabular}

OR: Odds ratio; $\operatorname{Exp}(\mathrm{B})$ : Coefficients; ${ }^{\star} p<0.05$ is considered statistically significant. Adjusted for age, the number of cerebral hemorrhage and contusion, BUN, troponin and BNP level. 
Table 5. Predictors for in-hospital mortality, length of in-hospital stay and ICU stay.

\begin{tabular}{|c|c|c|c|c|c|c|}
\hline \multirow{2}{*}{ Predictors } & \multicolumn{2}{|c|}{$\begin{array}{l}\text { Mortality in hospital } \\
\quad(\mathrm{OR}(95 \% \mathrm{Cl}))\end{array}$} & \multicolumn{2}{|c|}{$\begin{array}{l}\text { Length of in-hospital } \\
\text { stay }(\operatorname{Exp}(B)(95 \% \mathrm{Cl}))\end{array}$} & \multicolumn{2}{|c|}{$\begin{array}{c}\text { Length of in ICU } \\
\text { stay }(\operatorname{Exp}(B)(95 \% \mathrm{Cl}))\end{array}$} \\
\hline & Multivariable & $p$ & Multivariable & $p$ & Multivariable & $p$ \\
\hline Age & $\begin{array}{c}1.00 \\
(0.98-1.02)\end{array}$ & 0.982 & $\begin{array}{c}0.36 \\
(-0.01-0.71)\end{array}$ & $0.043^{*}$ & $\begin{array}{c}0.03 \\
(-0.15-0.20)\end{array}$ & 0.765 \\
\hline $\begin{array}{l}\text { Cardiac } \\
\text { function }\end{array}$ & $\begin{array}{c}3.17 \\
(1.44-6.95)\end{array}$ & $0.004^{*}$ & $\begin{array}{c}-8.43 \\
(-19.37-2.50)\end{array}$ & 0.130 & $\begin{array}{c}-0.32 \\
(-5.79-5.14)\end{array}$ & 0.908 \\
\hline GCS & $\begin{array}{c}0.94 \\
(0.86-1.03)\end{array}$ & 0.189 & $\begin{array}{c}-1.97 \\
(-3.16--0.78)\end{array}$ & $0.001^{*}$ & $\begin{array}{c}-1.49 \\
(-2.09--0.89)\end{array}$ & $<0.0001^{*}$ \\
\hline $\begin{array}{l}\text { Mechanical } \\
\text { ventilation }\end{array}$ & $\begin{array}{c}0.77 \\
(0.20-2.92)\end{array}$ & 0.696 & $\begin{array}{c}21.89 \\
(4.59-39.18)\end{array}$ & $0.013^{*}$ & $\begin{array}{c}4.02 \\
(-5.38-13.43)\end{array}$ & 0.400 \\
\hline $\begin{array}{l}\text { Vasopressors } \\
\text { use }\end{array}$ & $\begin{array}{c}0.17 \\
(0.01-3.88)\end{array}$ & 0.268 & $\begin{array}{c}-16.81 \\
(-72.59-38.96)\end{array}$ & 0.553 & $\begin{array}{c}-33.42 \\
(-60.97--5.86)\end{array}$ & $0.018^{*}$ \\
\hline
\end{tabular}

OR: Odds ratio; $\operatorname{Exp}(\mathrm{B})$ : Coefficients; ${ }^{*} p<0.05$ is considered statistically significant. Adjusted for age, gender, smoking, alcohol use, the number of stones, WBC level at hospital admission.

Table 6. Predictors for hospital mortality, hospital and ICU length of stay.

\begin{tabular}{|c|c|c|c|c|c|c|}
\hline \multirow{2}{*}{ Predictors } & \multicolumn{2}{|c|}{$\begin{array}{l}\text { Hospital mortality } \\
\quad(\mathrm{OR}(95 \% \mathrm{CI}))\end{array}$} & \multicolumn{2}{|c|}{$\begin{array}{l}\text { hospital length of stay } \\
(\operatorname{Exp}(B)(95 \% \text { CI }))\end{array}$} & \multicolumn{2}{|c|}{$\begin{array}{l}\text { ICU length of stay } \\
(\operatorname{Exp}(B)(95 \% \text { CI }))\end{array}$} \\
\hline & Multivariable & $p$ & Multivariable & $p$ & Multivariable & $p$ \\
\hline Age & $\begin{array}{c}1.00 \\
(0.98-1.02)\end{array}$ & 0.982 & $\begin{array}{c}0.36 \\
(-0.01-0.71)\end{array}$ & $0.043^{*}$ & $\begin{array}{c}0.03 \\
(-0.15-0.20)\end{array}$ & 0.765 \\
\hline $\begin{array}{l}\text { Cardiac } \\
\text { function }\end{array}$ & $\begin{array}{c}3.17 \\
(1.44-6.95)\end{array}$ & $0.004^{*}$ & $\begin{array}{c}-8.43 \\
(-19.37-2.50)\end{array}$ & 0.130 & $\begin{array}{c}-0.32 \\
(-5.79-5.14)\end{array}$ & 0.908 \\
\hline GCS & $\begin{array}{c}0.94 \\
(0.86-1.03)\end{array}$ & 0.189 & $\begin{array}{c}-1.97 \\
(-3.16--0.78)\end{array}$ & $0.001^{*}$ & $\begin{array}{c}-1.49 \\
(-2.09--0.89)\end{array}$ & $<.0001^{*}$ \\
\hline $\begin{array}{l}\text { Mechanical } \\
\text { ventilation }\end{array}$ & $\begin{array}{c}0.77 \\
(0.20-2.92)\end{array}$ & 0.696 & $\begin{array}{c}21.89 \\
(4.59-39.18)\end{array}$ & $0.013^{*}$ & $\begin{array}{c}4.02 \\
(-5.38-13.43)\end{array}$ & 0.400 \\
\hline $\begin{array}{l}\text { Vasopressors } \\
\text { use }\end{array}$ & $\begin{array}{c}0.17 \\
(0.01-3.88)\end{array}$ & 0.268 & $\begin{array}{c}-16.81 \\
(-72.59-38.96)\end{array}$ & 0.553 & $\begin{array}{c}-33.42 \\
(-60.97--5.86)\end{array}$ & $0.018^{*}$ \\
\hline
\end{tabular}

OR: Odds ratio; $\operatorname{Exp}(\mathrm{B})$ : Coefficients; ${ }^{\star} p<0.05$ is considered statistically significant. Adjusted for age, gender, smoking, alcohol use, WBC level at hospital admission.

length of stay using univariable and multivariable regression analyses. Factor associated with hospital mortality were cardiac function (OR $=3.17,95 \%$ CI 1.44 - 6.95, $p=0.004)$. Factors mainly associated with length of stay in hospital were age $(\operatorname{Exp}(B)=0.36,95 \%$ CI $0.01-0.71, p=0.043)$, GCSscore $(\operatorname{Exp}(B)=-1.97$ $95 \%$ CI $3.16--0.78, p<0.001)$, and use of mechanical ventilation $(\operatorname{Exp}(\mathrm{B})=$ 21.89, 95\% CI $4.59-39.18, p=0.013)$. GCSscore $(\operatorname{Exp}(\mathrm{B}) \quad=-1.495 \%$ CI 2.09 $-0.89, p<0.001)$, and use of vasopressor $(\operatorname{Exp}(\mathrm{B}) \quad=-33.4205 \% \mathrm{CI} 60.97$ $-0.86, p=0.018)$ were related factors associated with ICU length of stay. 


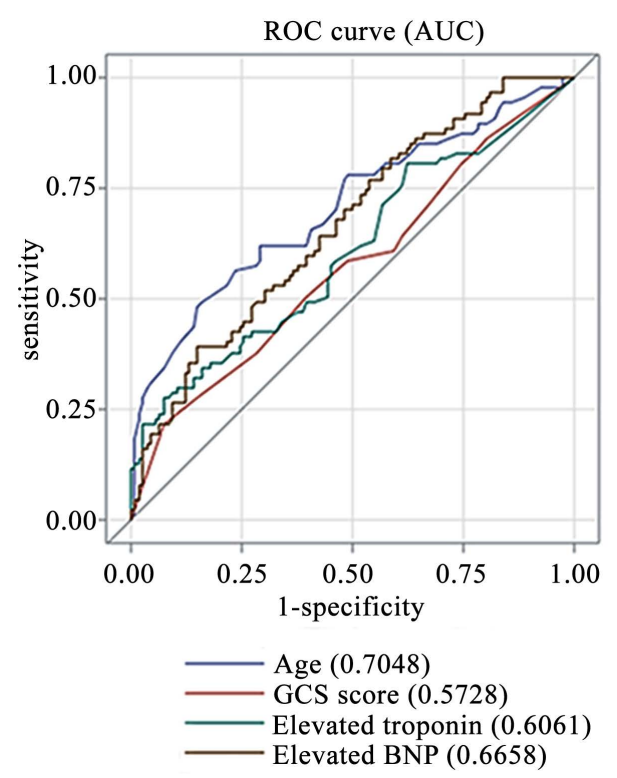

Figure 2. Age was good at predicting cardiac dysfunction with an area under the receiver operating characteristic curve (AUC) of 0.70 . The AUC of elevated cardiac enzymes (troponin and BNP) in predicting cardiac dysfunction was 0.61 and 0.66 , respectively.

\section{Discussion}

Neuro-cardiogenic dysfunction that follows brain injury can generally result in several complications such as electrolyte disturbance, related infection and prolonged ventilation, which can negatively impact prognosis of brain trauma and increase mortality and financial burden [13] [17] [18]. This retrospective study confirmed that worse clinical outcomes and longer ICU length of stay are common among patients with cardiac dysfunction after TBI, and cardiac abnormality was found to be an independent factor of clinical outcomes after adjusting confounders. The elevated cardiac enzymes (troponin-I and BNP) can be predicted cardiac dysfunction to a certain extent. Moreover, Age, GCS, and mechanical ventilation seem to be the main related factors for hospital length of stay, while ICU length of stay was associated with GCS and use of vasopressors. TBI patients who had cardiac dysfunction during ICU admission were associated with higher hospital mortality.

Cardiac dysfunction has been occurred and described in a variety of models of brain injury, such as subarachnoid hemorrhage (SAH) [5], stroke [19], and emotional stress [20], etc. The proposed mechanism for this neuro-cardiogenic dysfunction is thought to be excessive catecholamine level and inflammatory cascade [21] [22]. The clinical manifestations cardiac are varied by the existence of echocardiographic abnormalities and elevated cardiac enzymes are critical clues for early detection of cardiac dysfunction [6]. The present study reveals a tendency of abnormal echocardiograms for TBI patients who are older and have elevated levels of troponin-I and BNP. Similarly, another study showed that nearly half of the patients developed cardiac dysfunction as recorded by elevated troponin [13]. Meanwhile, a few published studies have revealed a strong clinical 
relationship between episodes of secondary neuro-cardiogenic dysfunction and the worst clinical outcome [23] [24]. The findings of our study are consistent with Ahmed et al. [13] who demonstrated a significantly higher in terms of mortality in patients with cardiac dysfunction after TBI. Hospital and ICU length of stay in the cardiac group tended to be longer, Furthermore, our data is in line with previous studies suggesting that secondary cardiac dysfunction after TBI was a risk factor for clinical outcomes [6] [25] [26]. Therefore, the presence of cardiac dysfunction most likely reflects a severe brain injury and predicts a poor outcome. Meanwhile, our result is consistent with recent studies demonstrating that elevated BNP and troponin were associated with poor cardiac prognosis [15] [27]. Early detection of troponin and BNP levels for cardiac dysfunction has a certain degree of warning. However, King et al. [28] reported that there was no significant correlation between troponin levels and clinical outcomes. Taken together, BNP or troponin could not guarantee a reliable prediction of clinical outcome in critically ill patients, and a comprehensive clinical assessment is essential.

We also investigated several variables affecting clinical outcomes. In the present study, cardiac function was considered the candidate influential factor for cure rate. The consciousness of the presence of cardiac dysfunction after TBI in these patients and its impact on clinical outcome might attract attention toward cardiac protection. Finding in our study, which mirrors that of David et al. and others [29] [30], is that age and GCS were significant predictors of mortality and discharge. GCS has been considered as a tool to classify the severity of neurologic disorders. In addition, age may affect the association between the severity of TBI and the neurologic conditions measured by GCS [31]. For Mechanical ventilation use, Lim et al. [32] suggested that life-saving interventions were not significant related with clinical outcomes. However, mechanical ventilation is commonly used in critically ill patients for requiring to support ongoing organ failure. Hospital length of stay is often prolonged due to inadequate mechanical ventilation. Therefore, this result needs more validation in larger studies.

The present study had several possible limitations that should be acknowledged. First, it is limited by its retrospective observational design. Second, the size of the study population was small. Strictly exclusion of patients might affect the generalizability of our study. Therefore, further larger prospective studies and intervention trials should be undertaken to confirm this causal association and to understand the underlying pathophysiology.

\section{Conclusion}

In summary, TBI patients with secondary cardiac dysfunction appear to be longer ICU length of stay, the higher hospital mortality. Cardiac dysfunction in the setting of TBI was found to be an independent risk factor of clinical outcomes through controlling confounding factors. Moreover, age, GCS, and mechanical ventilation seem to be the main related factors for hospital length of stay. GCS and use of vasopressors were associated with ICU length of stay. 


\section{Acknowledgements}

We sincerely appreciate Yidu Cloud Technology Ltd., Beijing, China for providing technical support in extracting data by using the big-data intelligence platform.

\section{Data Availability}

The datasets used and/or analyzed during the current study are available from the corresponding author on reasonable request.

\section{Funding}

Fujian Province Intensive Medical Center Construction Project (2017-510).

\section{Statement of Ethics}

The study protocol was approved by the hospital ethics committee.

\section{Conflicts of Interest}

The authors declare that they have no conflict of interest.

\section{References}

[1] Liu. B.Y. (2015) Current Status and Development of Traumatic Brain Injury Treatments in China. Chinese Journal of Traumatology, 18, 135-136. https://doi.org/10.1016/j.cjtee.2015.04.002

[2] Maas, R., Morganti-Kossmann, B. and Gruen, M. (2012) Early Management of Severe Traumatic Brain Injury. Lancet, 380, 1088-1098.

https://doi.org/10.1016/S0140-6736(12)60864-2

[3] Vavilala, M.S., Kernic, M.A., Wang, J., Kannan, N., Mink, R.B., Wainwright, M.S, Groner, J.I., Bell, M.J., Giza, C.C. and Zatzick, D.F. (2014) Acute Care Clinical Indicators Associated with Discharge Outcomes in Children with Severe Traumatic Brain Injury. Critical Care Medicine, 42, 2258-2266. https://doi.org/10.1097/CCM.0000000000000507

[4] Potapov, A.A., Krylov, V.V., Gavrilov, A.G., Kravchuk, A.D., Likhterman, L.B., Petrikov, S.S., Talypov, A.E., Zakharova, N.E., Oshorov, A.V., Sychev, A.A., et al. (2016) Guidelines for the Diagnosis and Treatment of Severe Traumatic Brain Injury. Part 2. Intensive Care and Neuromonitoring. Zhurnal Voprosy Neirokhirurgii imeni N N Burdenko, 80, 98-106.

[5] Moussouttas, M., Lai, E.W., Khoury, J., Huynh, T.T., Dombrowski, K. and Pacak, K. (2012) Determinants of Central Sympathetic Activation in Spontaneous Primary Subarachnoid Hemorrhage. Neurocritical Care, 16, 381-388.

https://doi.org/10.1007/s12028-012-9673-5

[6] Prathep, S., Sharma, D., Hallman, M., Joffe, A., Krishnamoorthy, V., Mackensen, G.B. and Vavilala, M.S. (2014) Preliminary Report on Cardiac Dysfunction after Isolated Traumatic Brain Injury. Journal of Emergency Medicine, 46, 602. https://doi.org/10.1016/j.jemermed.2014.02.021

[7] Juul, N., Morris, G.F., Marshall, S.B. and Marshall, L.F. (2000) Intracranial Hypertension and Cerebral Perfusion Pressure: Influence on Neurological Deterioration 
and Outcome in Severe Head Injury. Journal of Neurosurgery, 92, 1-6. https://doi.org/10.3171/jns.2000.92.1.0001

[8] Albanèse, J., Leone, M., Alliez, J.R., Kaya, J.M., Antonini, F., Alliez, B. and Martin, C. (2003) Decompressive Craniectomy for Severe Traumatic Brain Injury: Evaluation of The Effects at One Year. Critical Care Medicine, 31, 2535-2538.

[9] Shanlin, R.J., Sole, M.J., Rahimifar, M., Tator, C.H. and Factor, S.M. (1988) Increased Intracranial Pressure Elicits Hypertension, Increased Sympathetic Activity, Electrocardiographic Abnormalities and Myocardial Damage in Rats. Journal of the American College of Cardiology, 12, 730-736.

[10] Naidech, A.M., Kreiter, K.T., Janjua, N., Ostapkovich, N.D., Parra, A., Commichau, C., et al. (2005) Cardiac Troponin Elevation, Cardiovascular Morbidity, and Outcome after Subarachnoid Hemorrhage. Circulation, 112, 2851-2856. https://doi.org/10.1161/CIRCULATIONAHA.105.533620

[11] James, P., Ellis, C.J., Whitlock, R.M., Mcneil, A.R., Henley, J. and Anderson, N.E. (2000) Relation between Troponin T Concentration and Mortality in Patients Presenting with an Acute Stroke: Observational Study. BMJ, 320, 1502-1504. https://doi.org/10.1136/bmj.320.7248.1502

[12] Temes, R.E., Tessitore, E., Schmidt, J.M., Naidech, A.M., Fernandez, A., Ostapkovich, N.D., Frontera, J.A., Wartenberg, K.E., Tullio, M.R.D. and Badjatia, N. (2010) Left Ventricular Dysfunction and Cerebral Infarction from Vasospasm after Subarachnoid Hemorrhage. Neurocritical Care, 13, 359-365. https://doi.org/10.1007/s12028-010-9447-X

[13] Hasanin, A., Kamal, A., Amin, S., Zakaria, D., Sayed, R.E., Mahmoud, K. and Mukhtar, A. (2016) Incidence and Outcome of Cardiac Injury in Patients with Severe Head Trauma. Scandinavian Journal of Trauma Resuscitation \& Emergency Medicine, 24, Article No. 79. https://doi.org/10.1186/s13049-016-0263-y

[14] Najafipour, H., Khachaki, A.S., Khaksari, M., Shahouzehi, B., Joukar, S. and Poursalehi, H.R. (2014) Traumatic Brain Injury Has Not Prominent Effects on Cardiopulmonary Indices of Rat after 24 Hours: Hemodynamic, Histopathology, and Biochemical Evidence. Iranian Biomedical Journal, 18, 225-231.

[15] Ostermann, M., Lo, J., Toolan, M., Tuddenham, E., Sanderson, B., Lei, K., Smith, J. Griffiths, A., Webb, I. and Coutts, J. (2014) A Prospective Study of the Impact of Serial Troponin Measurements on the Diagnosis of Myocardial Infarction and Hospital and Six-Month Mortality in Patients Admitted to ICU with Non-Cardiac Diagnoses. Critical Care, 18, R62.

[16] Gelow, J., Kruer, M., Yadav, V. and Kaul, S. (2009) Apical Ballooning Resulting from Limbic Encephalitis. American Journal of Medicine, 122, 583-586.

https://doi.org/10.1016/j.amjmed.2008.12.016

[17] Inamasu, J., Nakatsukasa, M., Mayanagi, K., Miyatake, S., Sugimoto, K., Hayashi, T. Kato, Y. and Hirose, Y. (2012) Subarachnoid Hemorrhage Complicated with Neurogenic Pulmonary Edema and Takotsubo-Like Cardiomyopathy. Neurologia Medico-Chirurgica, 52, 49-55. https://doi.org/10.2176/nmc.52.49

[18] Cheung, R.T.F. and Hachinski, V. (2004) Cardiac Effects of Stroke. Current Treatment Options in Cardiovascular Medicine, 6, 199-207. https://doi.org/10.1007/s11936-996-0014-x

[19] Dias, V., Cabral, S., Meireles, A., Gomes, C., Antunes, N., Vieira, M., Caiado, L. and Torres, S. (2009) Stunned Myocardium Following Ischemic Stroke. Case Report. Cardiology, 113, 287-290. https://doi.org/10.1159/000205963

[20] Burdick, W. (2006) Neurohumoral Features of Myocardial Stunning Due to Sudden 
Emotional Stress. Yearbook of Cardiology, 2006, 295-298.

[21] Banki, N.M., Alexander, K., Dae, M.W., Jacob, M., Poyee, T., Lawton, M.T., Drew, B.J., Elyse, F., Wade, S. and Parmley, W.W. (2005) Acute Neurocardiogenic Injury after Subarachnoid Hemorrhage. Circulation, 112, 3314-3319. https://doi.org/10.1161/CIRCULATIONAHA.105.558239

[22] Mashaly, H.A. and Provencio, J.J. (2008) Inflammation as a Link between Brain Injury and Heart Damage: The Model of Subarachnoid Hemorrhage. Cleveland Clinic Journal of Medicine, 75, S26-S30.

[23] Koyfman, L., Brotfain, E., Kutz, R., Frenkel, A., Schwartz, A., Boniel, A., Zlotnik, A. and Klein, M. (2015) Epidemiology of New-Onset Paroxysmal Atrial Fibrillation in the General Intensive Care Unit Population and after Discharge from ICU. A Retrospective Epidemiological Study. Anaesthesiology Intensive Therapy, 47, 309-314.

[24] Seguin, P., Signouret, T., Brangier, B., Laviolle, B. and Malledant, Y. (2004) Incidence and Risk Factors of Atrial Fibrillation in a Surgical Intensive Care Unit. Critical Care Medicine, 32, 722-726.

[25] Angelantonio, E., Di Fiorelli, M., Toni, D., Sacchetti, M.L., Lorenzano, S., Falcou, A., Ciarla, M.V., Suppa, M., Bonanni, L. and Bertazzoni, G. (2005) Prognostic Significance of Admission Levels of Troponin I in Patients with Acute Ischaemic Stroke. Journal of Neurology Neurosurgery \& Psychiatry, 76, 76-81. http://dx.doi.org/10.1136/jnnp.2004.041491

[26] Coghlan, L.A., Hindman, B.J., Bayman, E.O., Banki, N.M., Gelb, A.W., Todd, M.M., Zaroff, J.G. and Investigators, I. (2009) Independent Associations between Electrocardiographic Abnormalities and Outcomes in Patients with Aneurysmal Subarachnoid Hemorrhage. Stroke, 40, 412-418.

https://doi.org/10.1161/STROKEAHA.108.528778

[27] Leenders, G.E., Boeck, B.W.L.D., Teske, A.J., Meine, M., Bogaard, M.D., Prinzen, F.W., Doevendans, P.A. and Cramer, M.J. (2012) Septal Rebound Stretch Is a Strong Predictor of Outcome after Cardiac Resynchronization Therapy. Journal of Cardiac Failure, 18, 404-412. https://doi.org/10.1016/j.cardfail.2012.02.001

[28] King, D.A., Codish, S., Novack, V., Barski, L. and Almog, Y. (2005) The Role of Cardiac Troponin I as a Prognosticator in Critically Ill Medical Patients: A Prospective Observational Cohort Study. Critical Care, 9, Article No. R390. https://doi.org/10.1186/cc3731

[29] Clark, D.E. and Ryan, L.M. (2002) Concurrent Prediction of Hospital Mortality and Length of Stay from Risk Factors on Admission. Health Services Research, 37, 631-645.

[30] Ong, A.W., Omert, L.A., Vido, D., Goodman, B.M., Protetch, J., Rodriguez, A. and Jeremitsky, E. (2009) Characteristics and Outcomes of Trauma Patients with ICU Lengths of Stay 30 Days and Greater: A Seven-Year Retrospective Study. Critical care, 13, Article No. R154. https://doi.org/10.1186/cc8054

[31] Rau, C.S., Wu, S.C., Chen, Y.C., Chien, P.C., Hsieh, H.Y., Kuo, P.J. and Hsieh, C.H (2017) Effect of Age on Glasgow Coma Scale in Patients with Moderate and Severe Traumatic Brain Injury: An Approach with Propensity Score-Matched Population. International Journal of Environmental Research and Public Health, 14, 1378. https://doi.org/10.3390/ijerph14111378

[32] Lim, W., Qushmaq, I., Cook, D.J., Crowther, M.A., Heels-Ansdell, D., Devereaux, P.J. (2005) Elevated Troponin and Myocardial Infarction in the Intensive Care Unit: A Prospective Study. Critical Care, 9, Article No. R636. https://doi.org/10.1186/cc3816 


\section{Abbreviations}

TBI: Traumatic Brain Injury; ICU: Intensive Care Unit; PSH: Paroxysmal Sympathetic Hyperactivity; ICP: Elevated Intracranial Pressure; LVEF: Left Ventricular Ejection Fraction; SICU: Surgical Intensive Care Unit; GCS: Glasgow Coma Scale; HGb: Hemoglobin; CRP: C-Reactive Protein; WBC: White Blood Cell count; PCT: Procalcitonin; CK-MB: Creatine phosphokinase MB isoenzyme; BNP: B-type Natriuretic Peptide; BUN: Blood Urea Nitrogen; Cr: Creatinine. 